\title{
Is There a Relationship Between the Severity of Preeclampsia and Fetal Renal Doppler Indices?
}

\author{
Elnaz Afsari', Fatemeh Abbasalizadeh ${ }^{1 *}$, Zahra Fardiazar', Saeedeh Shahali', Yousef Soltan Ahmadi'
}

\begin{abstract}
Objectives: Preeclampsia is a high prevalence complication in pregnancy and is responsible for $36 \%$ of maternal mortality worldwide. The offspring of mothers with preeclampsia face many problems after birth and in their lifetime. The fetal renal is one of the most vulnerable organs following maternal preeclampsia. In this regard, the present study investigated the relationship between the severity of preeclampsia and fetal renal artery resistance and pulsatility.

Materials and Methods: In general, 91 pregnant women were included and divided into control and preeclampsia groups. The control group included 43 women with normal pregnancy and the preeclampsia group consisted of 48 pregnant women who suffered from preeclampsia and were classified into patients in severe and non-severe preeclampsia groups each containing 24 cases. Renal artery Doppler ultrasound was performed, and then the systole/diastole ratio $(\mathrm{S} / \mathrm{D})$, pulsatility index $(\mathrm{PI})$, and resistance index (RI) were measured as well.

Results: The S/D ratio, RI, and PI significantly decreased in the preeclampsia group $(P<0.001)$ compared to the control group. The $\mathrm{S} / \mathrm{D}$ ratio in severe preeclampsia was significantly lower in comparison with non-severe preeclampsia $(P<0.001)$. Finally, the amniotic fluid index was related to the $\mathrm{PI}(P<0.05)$, and severe preeclampsia significantly increased the pregnancy termination before 34 weeks $(P<0.001)$

Conclusions: Preeclampsia deceased the resistance of renal arteries by altering the fetal renal blood flow. These changes can intensify in patients with severe preeclampsia compared to non-severe preeclampsia.

Keywords: Preeclampsia, Ultrasound, Doppler, Fetal, Renal
\end{abstract}

\section{Introduction}

Pregnancy is always associated with risks, and hypertensive disorders are not rare problems during pregnancy putting the mothers and their fetuses at risk and occasionally generating lifelong complications. Gestational hypertension is diagnosed when only hypertension with systolic blood pressure (BP) $\geq 140 \mathrm{~mm}$ $\mathrm{Hg}$ or diastolic BP $\geq 90 \mathrm{~mm} \mathrm{Hg}$ occurs after 20 weeks of gestational hypertension (1). When this hypertension is accompanied by proteinuria, thrombocytopenia, renal impairment, hepatic impairment, pulmonary edema, and cerebral/visual symptoms, it is called 'preeclampsia' (2), which occurs in $46 \%$ of pregnant women with gestational hypertension (3). Generally, 5\%-7\% of all pregnant women suffer from preeclampsia and it annually induces over 500000 fetal deaths and 70000 maternal deaths worldwide (4). In addition, preeclampsia increases the risk of maternal and fetal mortality, severe maternal and fetal morbidity, maternal intensive care unit admissions, preterm labor, cesarean section, and neonatal intensive care unit admissions (4-6). Indeed, the mechanism of preeclampsia is not fully understood, but given that the symptoms decrease when removing the placenta, the placenta can play a major role in preeclampsia (7). The only definitive treatment for preeclampsia is infant and placenta delivery (8).

Considering that the expression of hypoxia-inducible transcription factors and hypoxia-related genes (9), and (hypoxia-inducible factors $(-1 \alpha$ and $-2 \alpha)$, along with the markers of cellular oxygen deprivation (10) increases in the placenta of women who suffer from preeclampsia, hypoxia may have an important role in preeclampsia. Uteroplacental hypoxia induced by abnormal placentation in the early stage of pregnancy is common in pregnancies complicated by preeclampsia $(11,12)$. Preeclampsia decreases the cardiac output while increasing the systemic vascular resistance thus it influences different organs such as kidneys. According to some studies, the glomerular filtration rate (13) and resistance in maternal kidney and systolic/diastolic (S/D) ratios (14) reduced in pregnant women suffering from preeclampsia (15). Further, the level of thromboxane increases whereas the level of prostaglandins decreases in these mothers' blood and placenta (16). The studies on preeclampsia animal models have indicated that exposure to intrauterine hypoxia increased the risk of impaired fetal renal development while it decreased renal glomerular count, abnormal renal vascular tone, and activation of the renin-angiotensin- 


\section{Key Messages}

- Preeclampsia decreased the resistance in fetal renal arteries and these changes intensify in sever preeclampsia.

aldosterone system $(17,18)$. The offspring of mothers with preeclampsia face various problems after birth and in their lifetime. The kidneys of the fetus are affected by maternal preeclampsia because of blood pressure imbalances (19).

Due to the effect of blood pressure imbalance on the fetal renal flow, the present study attempted to determine the relationship between fetal renal vascular Doppler indices and the severity of preeclampsia in fetuses without abnormal intrauterine growth.

\section{Materials and Methods}

Study Design

In this prospective study, 91 pregnant women participated and were divided into two main groups. The control group encompassed 43 women who had a normal pregnancy, and the preeclampsia group contained 48 pregnant women who suffered from preeclampsia and were classified into two subgroups in severe $(\mathrm{n}=24)$ and non-severe $(n=24)$ preeclampsia groups, and all groups had similar obstetric history. Preeclampsia was diagnosed based on the International Society for the Study of Hypertension in Pregnancy guidelines. All participants were completely informed about this study and indicated their satisfaction to take part in this study, which was performed at AlZahra hospital in Tabriz, Iran during 2019-2020.

Maternal information was also recorded, including age, gravid, para, systolic and diastolic blood pressure, urinary protein, and the levels of plasma creatinine and liver enzymes. Renal artery Doppler ultrasound was performed by the PHILIPS ultrasonic device and with a wavelength of 1-7 MHz. The Doppler images of the abdominal aorta and renal arteries were examined in the coronal view (Figure 1). Color Doppler ultrasound was used to better view the arteries. The arterial flow was measured in the proximal part of the renal artery before branch separation and the angle of isonation was less than $30^{\circ}$ and close to zero. Measurements were done at the time between absent breathing and fetal movement (the fetus was immobile). Doppler indices including renal artery $S / D$ ratio, pulsatility index (PI), resistance index (RI), and the presence or absence of end-diastolic blood flow were measured in fetal immobility and absent respiration. All measurements were performed by an ultrasound specialist.

Finally, the correlations between S/D ratio, RI, and PI in renal arteries Doppler and the severity of preeclampsia, the severity of hypertension, increases in liver enzymes, proteinuria, increase of creatinine, platelets disorder, symptoms of preeclampsia, infant hospitalization, and neonatal APGAR were evaluated as well. The S/D ratio, RI, and PI in renal arteries Doppler were compared between

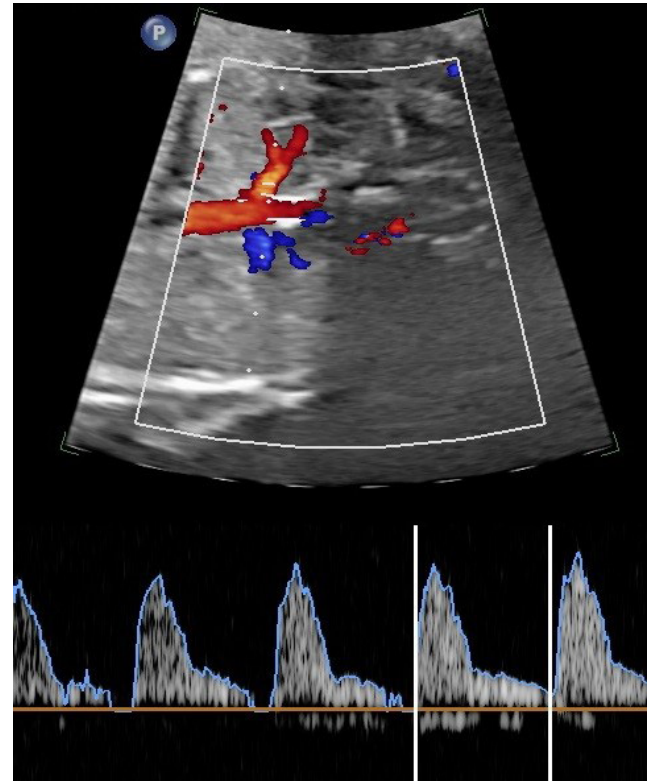

Figure 1. Fetal Renal Artery Doppler Measurement.

control and preeclampsia groups.

Inclusion and Exclusion Criteria

The inclusion criteria were mothers who had preeclampsia with a single pregnancy, normal growth of fetuses, and satisfaction to participate in the study. Mothers with abnormal fetal growth, abnormal amniotic fluid (AF) index, history of neurological disorders, abnormal pregnancies, twin and more pregnancies, some diseases (i.e., diabetes, chronic hypertension, ischemic heart disease, kidney disease, and autoimmune diseases), dissatisfaction to participate, and users of drugs or cigarettes were excluded from the study.

\section{Statistical Analysis}

The data were analyzed with SPSS statistical analysis software (version 22), and the descriptive statistics method was used to evaluate demographic variables. Quantitative data on renal artery Doppler indices were presented as the mean and standard deviation. Moreover, independent samples $t$ test, chi-square test, and regression logistic test were perfumed to compare the resistance of renal arteries, and a $P$ value less than 0.05 was considered statistically significant.

\section{Results}

Table 1 presents the demographics characteristics and $\mathrm{S} / \mathrm{D}$ ratio, $\mathrm{PI}, \mathrm{RI}$, and peak systolic velocity in renal and umbilical artery Doppler indices in control and preeclampsia groups. There was no significant difference in demographics characteristics and umbilical artery Doppler indices between the two groups. In renal artery Doppler, the S/D ratio, RI, and PI were significantly lower in the preeclampsia group compared to the control group $(P<0.001)$. 
Table 1. The Demographic Data and Renal and Umbilical Artery Doppler Indices of Control and Preeclampsia Groups

\begin{tabular}{lll}
\hline Variables & Control Group & Preeclampsia Group \\
Mean (SD) & PD) \\
\hline Gestational age & $32.19(3.63)$ & $33.08(2.94)$ \\
Maternal age & $29.81(3.46)$ & $31.19(6.75)$ \\
Maternal weight & $77.07(17.58)$ & $88.18(20.9)$ \\
Maternal height & $157.42(21.05)$ & $153.88(26.09)$ \\
Maternal BMI & $25.15(4.19)$ & $32.51(6.51)$ \\
AF index & $14.99(4.29)$ & $13.72(3.67)$ \\
S/D ratio in umbilical artery Doppler & $2.75(0.56)$ & $2.85(0.68)$ \\
RI in umbilical artery Doppler & $0.65(0.17)$ & $0.67(0.19)$ \\
PI in umbilical artery Doppler & $0.95(0.21)$ & $1.01(0.18)$ \\
PSV in umbilical artery Doppler & $43.76(9.48)$ & $44.72(13.86)$ \\
S/D ratio in renal artery Doppler & $7.58(3.8)$ & $2.8(0.62)$ \\
RI in renal artery Doppler & $0.86(0.05)$ & Ns \\
PI in renal artery Doppler & $2.35(0.63)$ & $0.66(0.18)$ \\
PSV in renal artery Doppler & $53.43(12.66)$ & $0.98(0.2)$ \\
\hline
\end{tabular}

Note. P<0.001: Statistically significant; SD: Standard deviation; Ns: Not significant; BMI: Body mass index; AF: Amniotic fluid; RT: Resistance index; PI: Pulsatility index; PSV: Peak systolic velocity.

Based on the relationship between the severity of preeclampsia and fetal renal artery Doppler indices (Table 2 ), the $S / D$ ratio in severe preeclampsia significantly decreased compared to non-severe preeclampsia $(P<0.001)$ and there were no significant differences between the two groups in terms of the RI and PI.

The results (Table 3 ) further revealed that the $\mathrm{S} / \mathrm{D}$ ratio and RI had no significant relationship with the AF index while the PI was significantly associated with the AF index $(P<0.05)$. However, none of the fetal renal artery Doppler indices demonstrated a significant relationship with fetal birth weight. The relationship between the severity of preeclampsia and pregnancy termination (Table 4) demonstrated that pregnancy termination before 34 weeks (gestational age) in severe preeclampsia was significantly more considerable compared to non-severe preeclampsia $(P<0.001)$.

No significant relationship was found between different variables (i.e., the severity of hypertension, increases in liver enzymes, proteinuria, and increases in creatinine, platelets disorder, symptoms of preeclampsia, infant hospitalization, and neonatal APGAR) and fetal renal artery Doppler indices (i.e., S/D ratio, PI, and RI). Eventually, the severity of preeclampsia had no significant effect on the AF index (the data are unavailable).

\section{Discussion}

Preeclampsia is a common complication in pregnancy that induces fetal and maternal morbidity and mortality. Totally, 5\%-7\% of pregnant women suffer from preeclampsia (4), and it is the cause of $39 \%$ of maternal deaths worldwide (20). Indeed, preeclampsia has many effects on maternal health during and after pregnancy. For example, the risk of chronic hypertension, cardiovascular disease (21), chronic kidney disease (22), and even endstage renal disease (23) is higher in these patients after pregnancy compared to other women. Considering a special intrauterine environment for the fetuses of these mothers, they experience more risk of pulmonary, cardiovascular, and metabolic diseases, systemic vascular dysfunction, and obesity in their lifetime (24-26). The fetal kidneys are influenced by the mother's preeclampsia, and the number of nephrons are decreased following blood pressure imbalances. Following placental hypoxia, the development of renal nerves impairs and induces the

Table 2. The Relationship Between the Severity of Preeclampsia and Fetal Renal Artery Doppler Indices

\begin{tabular}{|c|c|c|c|}
\hline \multirow{2}{*}{$\begin{array}{l}\text { Renal Artery } \\
\text { Doppler }\end{array}$} & \multicolumn{2}{|c|}{ Type of Preeclampsia } & \multirow[b]{2}{*}{ Statistical Analysis } \\
\hline & $\begin{array}{c}\text { Severe } \\
\text { Mean (SD) }\end{array}$ & $\begin{array}{l}\text { Non-severe } \\
\text { Mean (SD) }\end{array}$ & \\
\hline Number & 24 & 24 & \\
\hline$S / D$ ratio & $4.82(1.73)$ & $5.95(1.73)$ & $\begin{array}{c}\mathrm{T}: 2.72 \\
\mathrm{df}: 46 \\
P: 0.00\end{array}$ \\
\hline RI & $0.81(0.03)$ & $0.82(0.03)$ & $\begin{array}{c}\text { T: } 0.87 \\
\text { df: } 46 \\
P: 0.38\end{array}$ \\
\hline $\mathrm{PI}$ & $2.07(0.25)$ & $2.22(0.31)$ & $\begin{array}{c}\text { T: } 1.83 \\
\text { df: } 46 \\
P: 0.07\end{array}$ \\
\hline
\end{tabular}

Note. $P<0.001$ : Statistically significant; T: t-test; Df: Degrees of freedom; SD: Standard deviation; RI: Resistance index; PI: Pulsatility index.

Table 3. The Relationship Between AF Index and Birth Weight of Fetal With Renal Artery Doppler Indices

\begin{tabular}{lll}
\hline \multirow{2}{*}{ Renal Artery Doppler } & \multicolumn{2}{l}{ Statistical Analysis } \\
\cline { 2 - 3 } & AF Index & Birth Weight \\
\hline S/D ratio & $P: 0.54$ & $P: 0.12$ \\
RI & $P: 0.65$ & $P: 0.27$ \\
PI & $P: 0.03$ & $P: 0.16$ \\
\hline
\end{tabular}

Note. $P<0.05$ : Statistically significant; RI: Resistance index; PI: Pulsatility index; AF: Amniotic fluid. 
Table 4. The Relationship Between Severity of Preeclampsia and Termination of Pregnancy (week)

\begin{tabular}{|c|c|c|c|}
\hline \multirow[b]{2}{*}{ Type of Preeclampsia } & \multicolumn{2}{|c|}{ Termination of Pregnancy } & \multirow[b]{2}{*}{$P$ Value } \\
\hline & $\begin{array}{c}\text { Less than } 34 \text { weeks } \\
\text { No. }(\%)\end{array}$ & $\begin{array}{c}\text { More than } 34 \text { weeks } \\
\text { No. }(\%)\end{array}$ & \\
\hline Severe & $14(58.3)$ & $10(41.7)$ & \multirow{2}{*}{$<0.001$} \\
\hline Non-severe & $4(16.7)$ & $20(83.3)$ & \\
\hline
\end{tabular}

Note. $P<0.05$ : Statistically significant.

blood pressure imbalance in their lifetime (19).

In the physiological condition of a healthy mother's fetus, renin-angiotensin system activity is high in early pregnancy, thus contraction in renal arteries increases and the production of urine is low. Later, reninangiotensin system activity decreases, and subsequently, renal artery vasoconstriction decreases and thus leading to an increase in urine production, especially after 34 weeks. The fetal renin level is more than the maternal level and it is not related to maternal and placental renin levels $(27,28)$. Based on our result, the S/D ratio, RI, and PI in renal arteries decreased in the preeclampsia group in comparison to the control group, which is in line with the results of another study indicating that preeclampsia decreased the resistance of fetal renal arteries (29). The $\mathrm{S} / \mathrm{D}$ ratio in severe preeclampsia was significantly lower compared to non-severe preeclampsia while the RI and PI did not show significant differences. Therefore, the severity of preeclampsia can affect the resistance of renal arteries. The balance between vasoconstrictor and vasodilator factors determines the normal blood flow in renal arteries, and it seems that this balance had been lost in the fetus of mothers with preeclampsia (29) and this imbalance increases in severe preeclampsia.

The results of the present study demonstrated that the S/D ratio, RI, and PI had no relationship with increases in liver enzymes, proteinuria, and creatinine, as well as platelet disorder, symptoms of preeclampsia, infant hospitalization, and neonatal APGAR. To the best of our knowledge, no study has so far evaluated the relationship between S/D ratio, RI, and PI in renal arteries Doppler and the above-mentioned variable in pregnant women with preeclampsia. According to our result, the severity of preeclampsia had no effect on the AF index. One possible explanation for this discrepancy is that all mothers with an abnormal AF index and fetal growth were excluded from the study thus all of our participants had a normal AF index and fetal weight. The PI had a relationship with the AF index while none of the renal artery Doppler indices were related to fetal weight. The termination of pregnancy less than 34 weeks in severe preeclampsia was significantly more than that of non-severe preeclampsia, which is consistent with the findings of other studies confirming that the severity of preeclampsia increases the risk of preterm labor $(30,31)$. In this regard, it is suggested that future studies evaluate the changes in fetal blood biomarkers and the long-term effects of these changes on the life of the offspring. Our study had some limitations. It was impossible to compare preeclampsia and fetal growth restriction (FGR) because the mothers with FGR were excluded from the study, and our criteria for FGR was fetal weight less than $10 \%$. It is feasible that the circulation disorder has occurred before weight loss in fetuses with weight more than $10 \%$, and thus they had not excluded in the study.

\section{Conclusions}

In general, preeclampsia decreased the resistance of the renal arteries in the fetus of mothers with preeclampsia compared to the fetus of non-preeclampsia mothers, and these changes can intensify in patients with severe preeclampsia. This renal blood flow imbalance can influence offspring health in their lives, thus more prospective research is needed in this respect. The resistance of the fetus's renal arteries had no relationship with the increased liver enzymes, proteinuria, and creatinine in addition to platelet disorder, symptoms of preeclampsia, infant hospitalization, and neonatal APGAR. The risk of preterm labor in mothers with severe preeclampsia is more than in comparison with non-severe preeclampsia.

\section{Authors' Contribution}

EA: study concept and design and writing of draft; ZF, SS: data collection; YSA: data analysis and interpretation and statistical analysis; FA: study concept and design, study supervision, critical revision of manuscript, manuscript editing and drafting.

\section{Conflict of Interests}

Authors declare that they have no conflict of interests.

\section{Ethical Issues}

This study was approved by the ethical committee of Tabriz University of Medical Sciences (Ethics No. IR.TBZMED.REC.1400.259)

\section{Financial Support}

Women's Reproductive Health Research Center, Tabrize University of Medical Sciences, Tabriz, Iran supported the study.

\section{References}

1. Hypertension in pregnancy. Report of the American College of Obstetricians and Gynecologists' task force on hypertension in pregnancy. Obstet Gynecol. 2013;122(5):1122-1131. doi:10.1097/01.aog.0000437382.03963.88

2. Say L, Chou D, Gemmill A, et al. Global causes of maternal death: a WHO systematic analysis. Lancet Glob Health. 2014;2(6):e323333. doi:10.1016/s2214-109x(14)70227-x

3. Tranquilli AL, Dekker G, Magee L, et al. The classification, diagnosis and management of the hypertensive disorders of pregnancy: A revised statement from the ISSHP. Pregnancy Hypertens. 2014;4(2):97-104. doi:10.1016/j.preghy.2014.02.001

4. Kuklina EV, Ayala C, Callaghan WM. Hypertensive disorders and 
severe obstetric morbidity in the United States. Obstet Gynecol. 2009;113(6):1299-1306. doi:10.1097/AOG.0b013e3181a45b25

5. Hod T, Cerdeira AS, Karumanchi SA. Molecular mechanisms of preeclampsia. Cold Spring Harb Perspect Med. 2015;5(10). doi:10.1101/cshperspect.a023473

6. Khader YS, Batieha A, Al-Njadat RA, Hijazi SS. Preeclampsia in Jordan: incidence, risk factors, and its associated maternal and neonatal outcomes. J Matern Fetal Neonatal Med. 2018;31(6):770776. doi:10.1080/14767058.2017.1297411

7. Roberts JM, Hubel CA. The two stage model of preeclampsia: variations on the theme. Placenta. 2009;30(Suppl A):S32-37. doi:10.1016/j.placenta.2008.11.009

8. Turanov AA, Lo A, Hassler MR, et al. RNAi modulation of placental sFLT1 for the treatment of preeclampsia. Nat Biotechnol. 2018;36(12):1164-1173. doi:10.1038/nbt.4297

9. Rajakumar A, Brandon HM, Daftary A, Ness R, Conrad KP. Evidence for the functional activity of hypoxia-inducible transcription factors overexpressed in preeclamptic placentae. Placenta. 2004;25(10):763-769. doi:10.1016/j.placenta.2004.02.011

10. Soleymanlou N, Jurisica I, Nevo O, et al. Molecular evidence of placental hypoxia in preeclampsia. J Clin Endocrinol Metab. 2005;90(7):4299-4308. doi:10.1210/jc.2005-0078

11. Roberts JM. Pathophysiology of ischemic placental disease. Semin Perinatol. 2014;38(3):139-145. doi:10.1053/j. semperi.2014.03.005

12. Korkes HA, De Oliveira L, Sass N, Salahuddin S, Karumanchi SA, Rajakumar A. Relationship between hypoxia and downstream pathogenic pathways in preeclampsia. Hypertens Pregnancy. 2017;36(2):145-150. doi:10.1080/10641955.2016.1259627

13. Conrad KP, Stillman IE, Lindheimer MD. The kidney in normal pregnancy and preeclampsia. In: Taylor RN, Roberts JM, Cunningham FG, Lindheimer MD, eds. Chesley's Hypertensive Disorders in Pregnancy. 4th ed. San Diego: Academic Press; 2015:335-377. doi:10.1016/b978-0-12-407866-6.00016-x

14. Kublickas M, Lunell NO, Nisell $H$, Westgren M. Maternal renal artery blood flow velocimetry in normal and hypertensive pregnancies. Acta Obstet Gynecol Scand. 1996;75(8):715-719. doi:10.3109/00016349609065733

15. Charles N, Amarachukwu N, Ekpo E, Cajethan E. Changes in renal function among women with preeclampsia in a tertiary health institution in Nigeria. Int J Womens Health Reprod Sci. 2020;8(3):272-275

16. Mousa AA, Strauss JF 3rd, Walsh SW. Reduced methylation of the thromboxane synthase gene is correlated with its increased vascular expression in preeclampsia. Hypertension. 2012;59(6):12491255. doi:10.1161/hypertensionaha.111.188730

17. Walton SL, Bielefeldt-Ohmann H, Singh RR, et al. Prenatal hypoxia leads to hypertension, renal renin-angiotensin system activation and exacerbates salt-induced pathology in a sex-specific manner.
Sci Rep. 2017;7(1):8241. doi:10.1038/s41598-017-08365-4

18. Tang J, Zhu Z, Xia S, et al. Chronic hypoxia in pregnancy affected vascular tone of renal interlobar arteries in the offspring. Sci Rep. 2015;5:9723. doi:10.1038/srep09723

19. Lu HQ, Hu R. Lasting effects of intrauterine exposure to preeclampsia on offspring and the underlying mechanism. AJP Rep. 2019;9(3):e275-e291. doi:10.1055/s-0039-1695004

20. Schutte JM, Steegers EA, Schuitemaker NW, et al. Rise in maternal mortality in the Netherlands. BJOG. 2010;117(4):399-406. doi:10.1111/j.1471-0528.2009.02382.x

21. Bellamy L, Casas JP, Hingorani AD, Williams DJ. Pre-eclampsia and risk of cardiovascular disease and cancer in later life: systematic review and meta-analysis. BMJ. 2007;335(7627):974. doi:10.1136/bmj.39335.385301.BE

22. Vikse BE. Pre-eclampsia and the risk of kidney disease. Lancet. 2013;382(9887):104-106. doi:10.1016/s0140-6736(13)60741-2

23. Vikse BE, Irgens LM, Leivestad $T$, Skjaerven $R$, Iversen BM. Preeclampsia and the risk of end-stage renal disease. $N$ Engl J Med. 2008;359(8):800-809. doi:10.1056/NEJMoa0706790

24. Jayet PY, Rimoldi SF, Stuber T, et al. Pulmonary and systemic vascular dysfunction in young offspring of mothers with preeclampsia. Circulation. 2010;122(5):488-494. doi:10.1161/ circulationaha.110.941203

25. Stojanovska V, Scherjon SA, Plösch T. Preeclampsia as modulator of offspring health. Biol Reprod. 2016;94(3):53. doi:10.1095/ biolreprod.115.135780

26. Ahmadi M, Ganji J, Zamanfar D, Ghobadi Golafshani P. Investigation of the relationship between exposure to preeclampsia and overweight/obesity in 2-7 year old children. Int J Womens Health Reprod Sci. 2020;8(3):290-296.

27. Sulemanji M, Vakili K. Neonatal renal physiology. Semin Pediatr Surg. 2013;22(4):195-198. doi:10.1053/j. sempedsurg.2013.10.008

28. Boubred F, Grandvuillemin I, Simeoni U. Pathophysiology of fetal and neonatal kidneys. In: Buonocore G, Bracci R, Weindling M, eds. Neonatology: A Practical Approach to Neonatal Diseases. Milano: Springer; 2012:1018-1026. doi:10.1007/978-88-4701405-3_124

29. Ma'ayeh M, Krishnan V, Gee SE, Russo J, Shellhaas C, Rood KM. Fetal renal artery impedance in pregnancies affected by preeclampsia. J Perinat Med. 2020. doi:10.1515/jpm-2020-0024

30. Mihu D, Razvan C, Malutan A, Mihaela C. Evaluation of maternal systemic inflammatory response in preeclampsia. Taiwan J Obstet Gynecol. 2015;54(2):160-166. doi:10.1016/j.tjog.2014.03.006

31. Madazli R, Yuksel MA, Imamoglu M, et al. Comparison of clinical and perinatal outcomes in early- and late-onset preeclampsia. Arch Gynecol Obstet. 2014;290(1):53-57. doi:10.1007/s00404014-3176-x

(C) 2021 The Author(s); This is an open-access article distributed under the terms of the Creative Commons Attribution License (http:// creativecommons.org/licenses/by/4.0), which permits unrestricted use, distribution, and reproduction in any medium, provided the original work is properly cited. 